\title{
Feds to create surveillance system for drug-resistant bugs
}

A fter five years of inaction, the federal government is finally moving toward creating a national surveillance system to monitor drug-resistant micro-organisms.

The Public Health Agency of Canada (PHAC), which halted the Canadian Committee on Antimicrobial Resistance in 2009 but promised to step up to the plate, will finally deliver its blueprint for a new system in July, according to an internal plan released to the CMAJ.

Surveillance Strategic Plan, 20132016 states that PHAC recognizes the need for change, given that there is "no overarching agreement on integrated approaches to surveillance."

Details on how the plan will work will be released in July's blueprint. Spokesperson Robert Cyrenne stated in an email that the blueprint will outline the core elements of the new national surveillance system and provide specific actions to transform the existing system.

National leadership on surveillance is long overdue, according to experts who say there is little coordination between the federal and provincial levels.

"We are right at the edge of having substantial problems with infections we can't treat," says Dr. Allison McGeer, director of the Infectious Diseases Epidemiology Research Unit at Mount Sinai Hospital in Toronto, Ontario. "We do not have surveillance systems and we don't have adequate mechanisms to deal with it."

There is a two-pronged approach to dealing with antimicrobial resistance, says McGeer: using antimicrobials wisely and preventing infections where the resistant bugs are the most prevalent.

But first, Canada needs sufficient surveillance data, she says.

A 2011 internal government report identified antimicrobial resistance as a "growing problem," but the actual scope of the issue remains unknown because the current surveillance systems collect limited data. Most surveillance is now conducted by the Canada Nosocomial Infection Surveillance Program (CNISP) and the Canadian Inte-

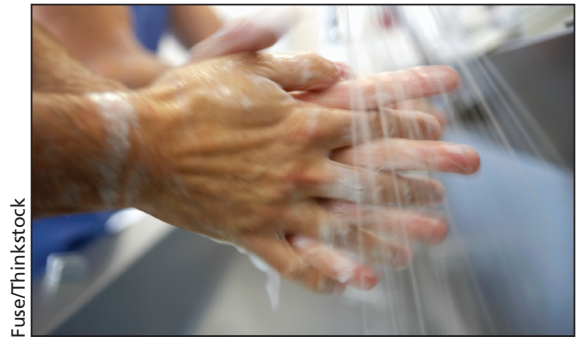

Both hospital and community infections will be monitored through PHAC's new surveillance blueprint.

grated Program for Antimicrobial Resistance Surveillance (CIPARS).

CNISP monitors antimicrobialresistant organisms in hospitals, but the information it collects represents only slightly more than $35 \%$ of all hospital admissions. This isn't enough, says Dr. Gary Garber, medical director of Infection Prevention and Control at Public Health Ontario.

CIPARS has initiatives to track antimicrobial-resistant bacteria in humans, animals and foods. PHAC says that CIPARS will review its human surveillance this year with a view to increasing the number of samples collected and will begin testing for Campylobacter.

Overarching problems with both of these programs are their susceptibility to budgetary cuts and their piecemeal approach, says Dr. John Conly, professor of medicine at the University of Calgary in Alberta. For more than a decade, experts have been calling for a more coordinated national system with federal leadership, he says.

Conly calls Canada's efforts "an international embarrassment." The United States and countries in the European Union, such as Sweden and Denmark, have monitored these pathogens nationally since the mid-1990s. Systems in these countries provide a comprehensive view of resistance in hospitals and agriculture.

McGeer welcomes any progress in Canada's current system, but says a mechanism for being able to watch what's going on in hospitals is needed. "We just don't have that mechanism in Canada." - Michaela Kostron, CMAJ

CMAJ 2014. DOI:10.1503/cmaj.109-4792 